\title{
Решения компании MORNSUN для систем питания в умных приложениях
}

\author{
В. Ежов
}

УДК 621.314 | ВАК 05.27.01

\begin{abstract}
Развитие новых технологий невозможно без внедрения эффективных и надежных источников питания, соответствующих возрастающим требованиям умных приложений. Разработчики систем питания стремятся найти оптимальное с точки зрения характеристик и стоимости решение для конкретного приложения. Среди производителей устройств силовой электроники следует выделить компанию MORNSUN, которая предлагает широкий выбор высокоэффективных и недорогих компонентов для построения источников питания для умных систем, а также решения, адаптированные к проекту заказчика. Рассмотрим решения компании для систем питания на примере таких перспективных приложений, как Интернет вещей и железнодорожный транспорт.
\end{abstract}

\section{РЕШЕНИЯ ДЛЯ ИНТЕРНЕТА ВЕЩЕЙ}

Технология Интернета вещей (ІІТ), которая стремительно входит в повседневную жизнь, открывает новые возможности для создания умных приложений, например, обеспечивающих управление замком входной двери вашего дома со смартфона или удаленную регулировку температуры воздуха в помещении. Такие устройства называют умными (умный замок или умный термостат), поскольку способность передавать и получать данные позволяет им принимать решения без физического присутствия человека.

Датчики и другие устройства Интернета вещей нуждаются в компактном и высокоэффективном источникепитания. Все умные системы должны быть оснащены преобразователями питания на входе, а также интерфейсами для передачи данных, такими как RS232/RS485 или CANBus. Компания MORNSUN предлагает решения для систем питания для растущего рынка ІоT, соответствующие всем перечисленным требованиям, в частности, они обеспечивают широкий диапазон напряжений, надежную изоляцию, точное и стабильное напряжение на выходе, отличаются компактными габаритами. В состав решений для ІоТ входит более 50 различных продуктов: AC/DC-преобразователи мощностью от 1 до 60 Вт, DC/DC-преобразователи мощностью от 200 мВт до 250 Вт, контроллеры шин RS232/RS485/CANBus. Напряжение изоляции этих устройств находится в диапазоне от 1000 до 6000 В.

Рассмотрим некоторые типичные приложения, в которых используются перечисленные виды продуктов.

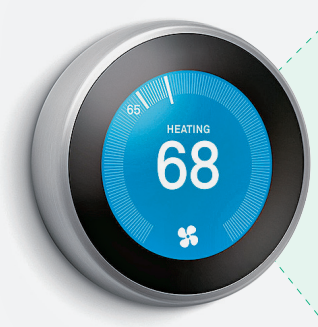

Умный термостат

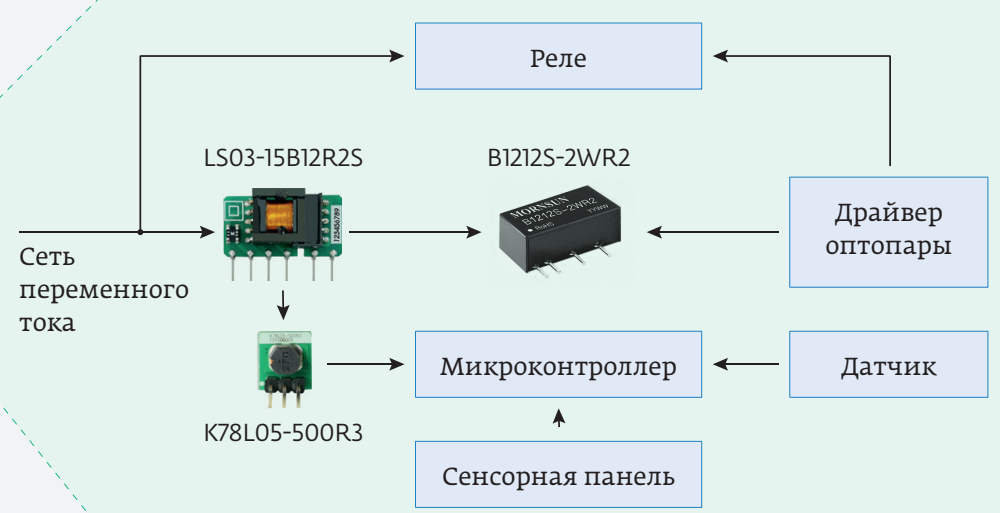

Рис. 1.

Система вентиляции и кондиционирования воздуха 


\section{Умный термостат}

Одно из наиболее широко распространенных в современных домах устройств с ІоТ-возможностями - умный термостат, для которого нужен недорогой и компактный источник питания с очень малым входным током. Компания MORNSUN предлагает универсальное решение. AC/DC-преобразователь LS03-15B12R2S мощностью 3 ВT и габаритами $35 \times 18 \times 11$ мм обеспечивает на выходе постоянное напряжение, используемое для питания драйвера оптопары через изолированный высокоинтегрированный DC/DC-преобразователь B1212S-2WR2 мощностью 2 Вт (рис. 1). Тот же AC/ DC-преобразователь снабжает питанием системный микроконтроллер через высокоэффективный DC/ DC-преобразователь K78L05-500R3, который оснащен защитой от короткого замыкания на выходе и обеспечивает входной ток без нагрузки всего 0,2 мА.

\section{Контроллер умной теплицы}

Сельское хозяйство - еще одна отрасль, в которой внедряется технология ІоТ. Типичный пример умного устройства - контроллер теплицы. Система должна обеспечивать питание для различных актуаторов, управляющих температурой, влажностью, интенсивностью освещения и внесением удобрений на основе информации от разнообразных датчиков. Актуаторы и датчики питаются, как правило, от источника с постоянным напряжением 24 В, но первичный источник питания - сеть переменного тока. Как показано на рис. 2, AC/ DC-преобразователь LI120-20B24R2 с монтажом на DIN-рейку обеспечивает на выходе напряжение постоянного тока 24 В для питания датчиков и актуаторов. DC / DC-преобразователь с напряжением изоляции 3 кB WRF2405S-3WR2 мощностью 3 Вт, который оснащен схемой защиты от короткого замыкания с самовосстановлением, снабжает напряжением питания 5 В основной блок управления и дисплей.

\section{РЕШЕНИЯ ДЛЯ ЖЕЛЕЗНОДОРОЖНОГО ТРАНСПОРТА}

Совершенствование железнодорожного транспорта требует внедрения решений для систем питания, соответствующих не только перспективам развития индустрии, но и положениям текущих отраслевых стандартов. Подвижной состав включает в себя множество систем, требующих эффективныхи надежных силовыхкомпонентов, - начиная от довольно очевидных приложений, таких как интегрированные коммуникационные системы, и заканчивая системами, о наличии которых обычные пассажиры и не догадываются, например системами сигнализации перегрева осей вагона. Современный поезд не может работать без компонентов для систем питания, которые способны работать в жестких условиях окружающей среды и широком

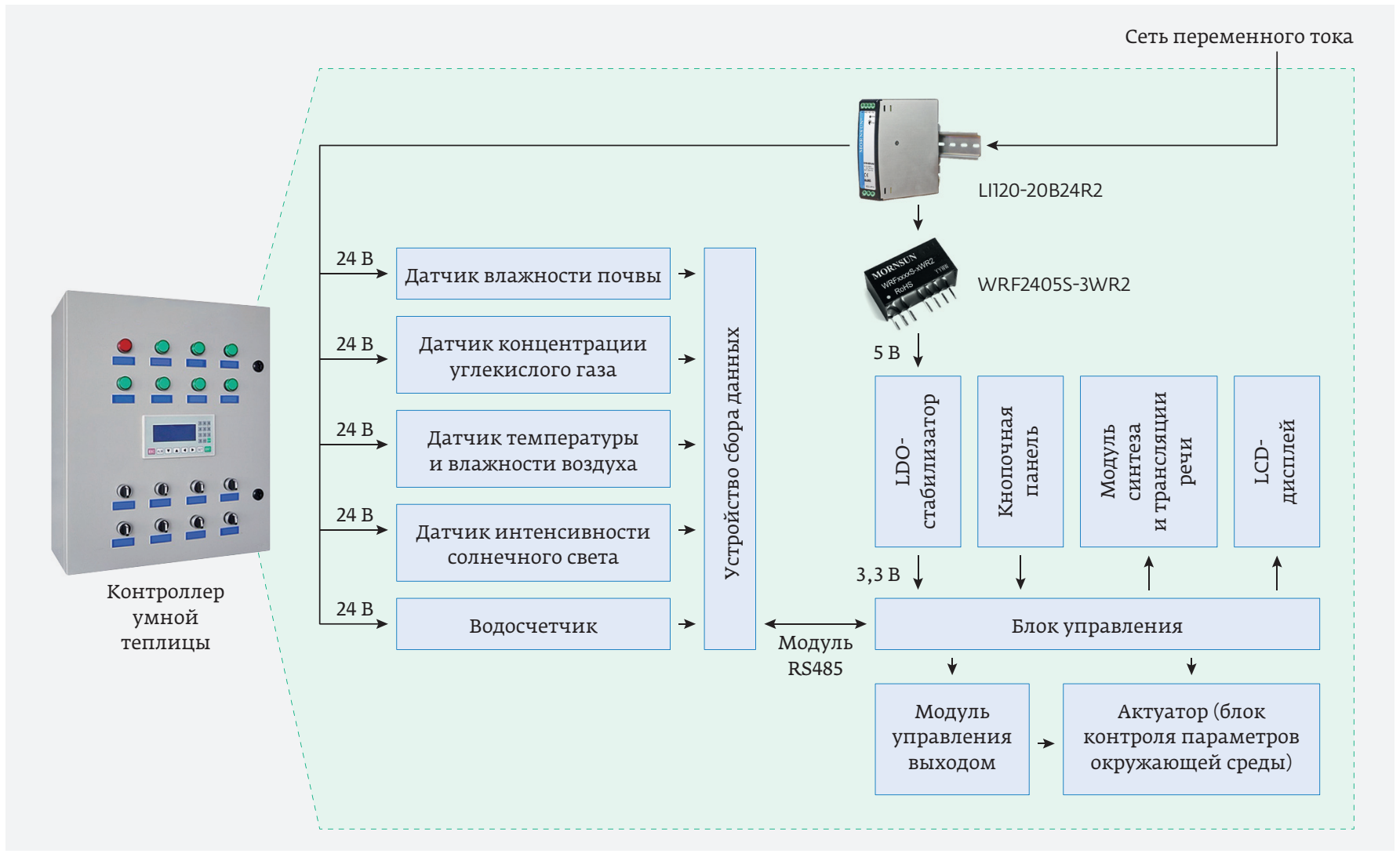

Рис. 2. Контроллер сельскохозяйственной теплицы 
диапазоне входных напряжений, обеспечивая безопасность как электронных систем, так и пассажиров.

Общепринятыми отраслевыми стандартами для электронного оборудования подвижного состава (EN50155 в Европе, ТВ /Т3021 - в Китае) предусмотрено пять критичных требований к системам питания на железнодорожном транспорте: широкий диапазон входных напряжений, электромагнитная совместимость (ЭМС), стойкость к механическим ударам и вибрации, невосприимчивость к изменению температуры и влажности, а также надежная электрическая изоляция

Входные напряжения должны соответствовать номиналам аккумуляторных батарей, используемых в подвижном составе: 24, 28, 36, 48, 72, 96 и 110 В. ЭМС критична из-за возможных электромагнитных помех, которые возникают между электрическими и электронными системами поезда, такими как источники питания и устройства передачи сигналов. Любое решение для системы питания должно функционировать в жестких условиях окружающей среды, к которым относятся вибрация и внезапные удары, вызванные движением поезда, экстремальные температуры (их возможное изменение в диапазоне от -30 до $60^{\circ} \mathrm{C}$ ) и повышенная влажность (от средних значений на уровне 75\% до воздействия воды). Электрическая изоляция позволяет предотвратить повреждение других компонентов системы, когда часть из них выходит из строя.

\section{Прислонно-сдвижные двери поезда}

Пример, иллюстрирующий проектное решение для системы питания на железнодорожном транспорте и хорошо известный всем пассажирам, - прислонно-сдвижные двери (рис. 3). Содержащиеся в них панели раздвигаются

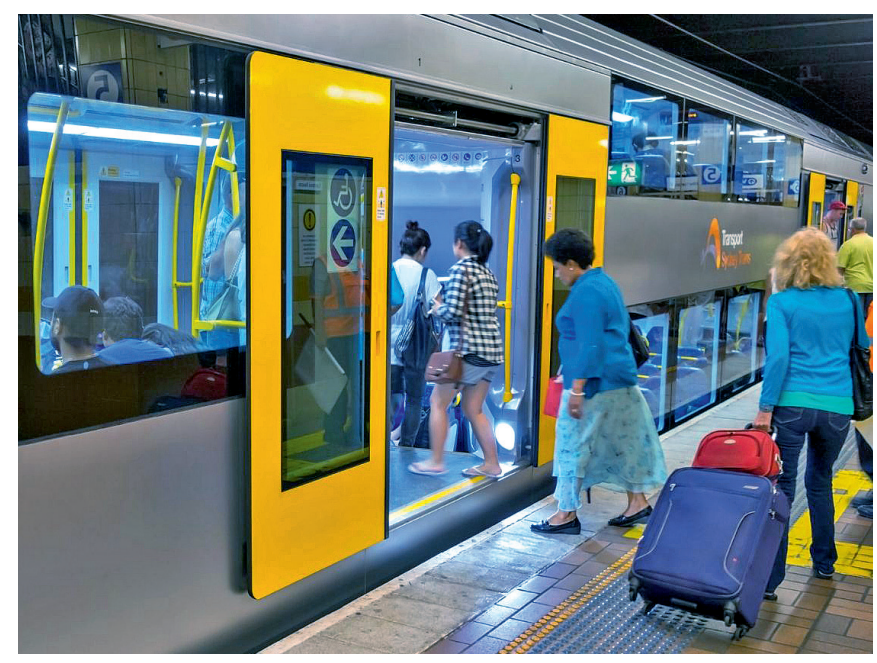

Рис. 3. Прислонно-сдвижные двери в железнодорожном вагоне

параллельно с внешней стороны вагона, герметично перекрывают дверной проем, используя разность давления на разных сторонах панелей. Двери приводятся в движение электродвигателем и редуктором, а управляются специальным блоком.

Блок управления дверьми (рис. 4) передает информацию о состоянии двери (данные контроля безопасности, положение аварийного выключателя и другие параметры) в кабину управления. Команды из кабины управления поступают в центральный процессор блока управления дверьми на их открытие и закрытие.

Как показано на рис. 4, напряжение 110 B DC для питания блока управления дверьми поступает через фильтр ЭМС.

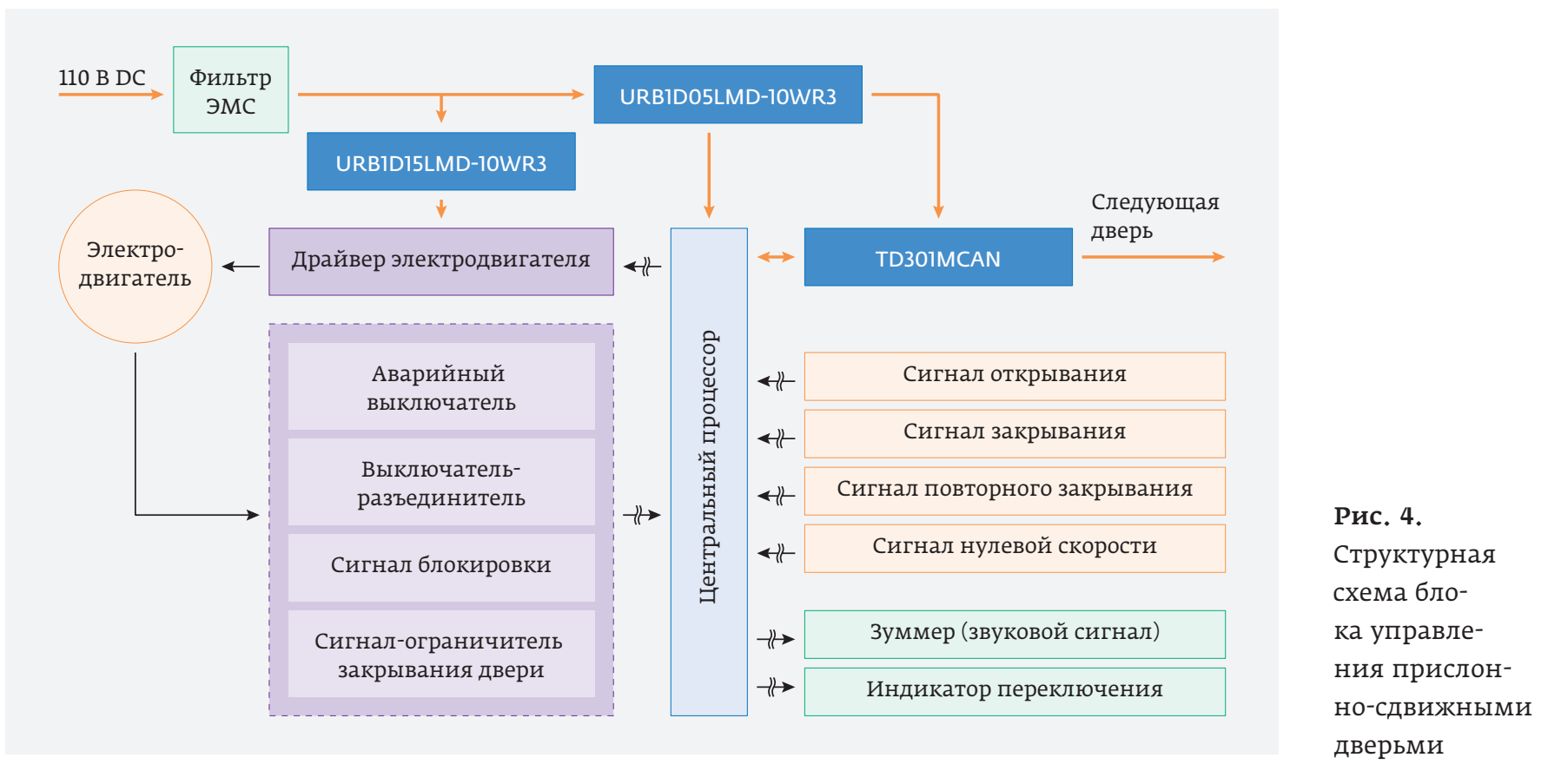



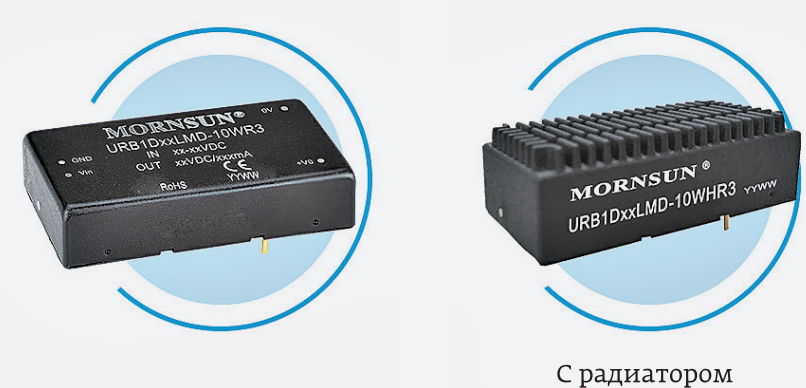

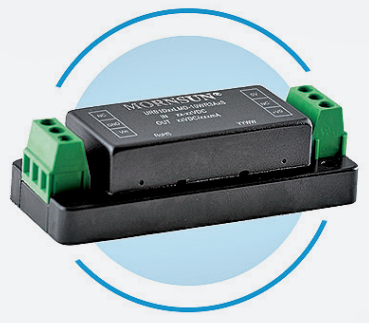

Монтаж на шасси

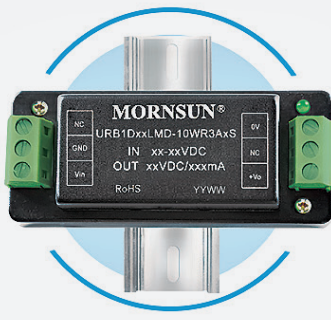

Монтаж на DIN-рейку

Рис. 5. URB1DxxLMD-10WR3 - серия высокоэффективных DC/DC-преобразователей от MORNSUN

Это напряжение требуется для питания драйвера электродвигателя и ЦП, необходимо также обеспечить развязку ЦП и электродвигателя, чтобы гарантировать электробезопасность и защиту от синфазных помех. Поэтому рекомендуется применять два мощных DC/ DC-преобразователя. Например, можно использовать 10-Вт устройства компании MORNSUN: URB1D05LMD-10WR3 с выходным напряжением 5 В для питания ЦП и URB1D15LMD-10WR3 с выходным напряжением 15 В для питания микросхемы драйвера электродвигателя.

DC/DC-преобразователи серии URB1DxxLMD-10WR3 это устройства третьего поколения, соответствующие всем требованиям, предъявляемым к железнодорожным приложениям (рис. 5). Они отличаются ударо- и виброустойчивостью, широким рабочим диапазоном температур, стойкостью к повышенной влажности и другим неблагоприятным условиям окружающей среды.

Эти устройства - прекрасный выбор для силовых приложений на железнодорожном транспорте, поскольку отвечают требованиям стандарта EN50155, подходят для транспортного электронного оборудования с напряжением питания 72/96/110 В, соответствуют специальным требованиям по изоляции и обеспечивают высокую эффективность (до 85\%). Для преобразователей этой серии характерны напряжение изоляции 2250 B DC (усиленная изоляция) и ультраширокий диапазон входных напряжений (от 40 до 160 В DC). Устройства оснащены различными схемами защиты, в том числе от падения напряжения на входе, от короткого замыкания на выходе, от перегрузок по Tоку и напряжению. Кроме того, серия URBIDxxLMD-10WR3 отличается низким уровнем пульсаций и помех.

Устройства мощностью 10 Вт выпускаются в металлическом корпусе со стандартным расположением выводов. Bce DC/DC-преобразователи от MORNSUN полностью герметизированы эпоксидным компаундом, который обеспечивает устойчивость ко всем механическим нагрузкам подвижного состава. Они также отличаются высокими тепловыми характеристиками. Благодаря широкому температурному диапазону (от -40 до $85^{\circ} \mathrm{C}$ ) устройства можно использовать в поезде повсеместно: от пассажирского салона до технических шкафов, где они подвергаются воздействию наружной температуры и других неблагоприятных факторов.

$$
\because *
$$

MORNSUN предлагает широкий набор продуктов для систем питания в умных приложениях для различных перспективных областей, в том числе Интернета вещей и железнодорожного транспорта. На базе этих устройств можно создавать высокоэффективные и экономичные решения, соответствующие требованиям отраслевых стандартов.

\section{ЗАО "Руднев-Шиляев"}

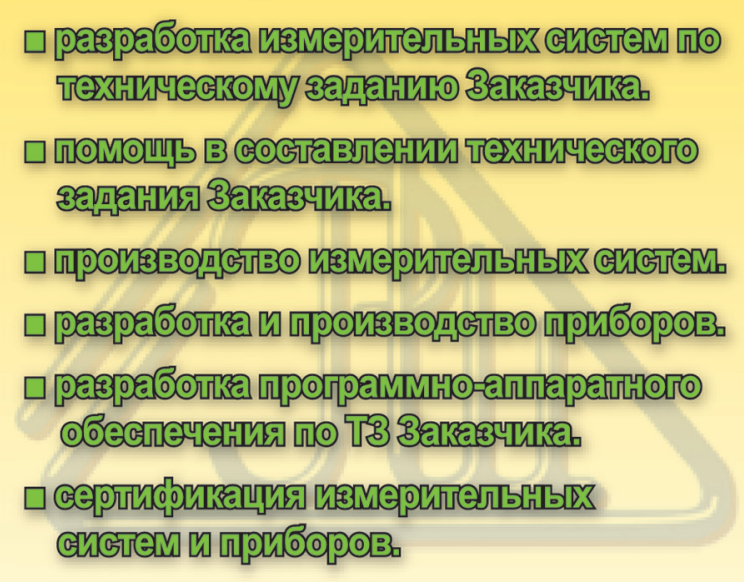

\section{Инструментальныерешения задач заказчикар}

125130, г. Москва, ул. Клары Цеткин, д. 33 корп. 35 www.rudshel.ru, e-mail: adc@rudshel.ru тел./факс: (495) 787-6367, 787-6368 